\title{
Carbon-Ion Beams Efficiently Induce Cell Killing in X-Ray Resistant Human Squamous Tongue Cancer Cells
}

\author{
Akihisa Takahashi ${ }^{1,2}{ }^{*}$, Hongyu $\mathrm{Ma}^{2}$, Akiko Nakagawa ${ }^{2}$, Yukari Yoshida ${ }^{3}$, Tatsuaki Kanai ${ }^{3}$, \\ Tatsuya Ohno ${ }^{3}$, Yoshikazu Kuwahara4, Manabu Fukumoto4, Takashi Nakano ${ }^{2,3}$ \\ ${ }^{1}$ Advanced Scientific Research Leaders Development Unit, Gunma University, Gunma, Japan \\ ${ }^{2}$ Department of Radiation Oncology, Gunma University Graduate School of Medicine, Gunma, Japan \\ ${ }^{3}$ Gunma University Heavy Ion Medical Center, Gunma, Japan \\ ${ }^{4}$ Department of Pathology, IDAC, Tohoku University, Sendai, Japan \\ Email: ${ }^{*}$ a-takahashi@gunma-u.ac.jp
}

Received 22 May 2014; revised 21 June 2014; accepted 21 July 2014

Copyright (C) 2014 by authors and Scientific Research Publishing Inc.

This work is licensed under the Creative Commons Attribution International License (CC BY). http://creativecommons.org/licenses/by/4.0/

cC) (i) Open Access

\begin{abstract}
In order to see whether carbon ion ( $\mathrm{C}$-ion) beams have a biological advantage over $\mathrm{X}$-rays, studies were designed to examine the effects of $\mathrm{C}$-ion beams on radiosensitivity in $\mathrm{X}$-ray resistant cells. Clinically relevant $\mathrm{X}$-ray resistant SAS-R cells derived from human tongue cancer SAS cells were used. The cells were exposed to X-rays or Spread-Out Bragg peak (SOBP) beam C-ions. Cell survival was measured using a modified high-density survival assay. Cell survival signaling and cell death signaling were analyzed using flow cytometry. The cells were labeled with putative cancer stem cell markers such as CD44 and CD326. SAS-R cells were 1.6 times more radioresistant than SAS cells after exposure to $\mathrm{X}$-rays. Cell survival was similar in each cell line after exposure to $\mathrm{C}$-ion beams. SAS-R cells displayed enhanced cell survival signaling when compared to SAS cells under normal conditions. On the other hand, the phosphorylation of AKT-related proteins decreased and polycaspase activities were enhanced when cells were irradiated with C-ion beams in both cell lines. More CD44 and CD326 positive cells were seen in SAS-R cells than in SAS cells. Moreover, the marker positive cell numbers significantly decreased after exposure to $C$-ion beams when compared to X-rays at iso-survival doses in SAS-R cells. C-ion beams efficiently induced cell killing in $X$-ray resistant cells which displayed activated cell survival signaling and contained more numerous cancer stem-like cells.
\end{abstract}

\section{Keywords}

Carbon-Ion Beams, X-Ray Resistant Cells, Cell Survival and Death Signaling, Cancer Stem-Like Cells

*Corresponding author.

How to cite this paper: Takahashi, A., et al. (2014) Carbon-Ion Beams Efficiently Induce Cell Killing in X-Ray Resistant Human Squamous Tongue Cancer Cells. International Journal of Medical Physics, Clinical Engineering and Radiation Oncology, 3, 133-142. http://dx.doi.org/10.4236/ijmpcero.2014.33019 


\section{Introduction}

Radiotherapy (RT) is one of the major therapeutic modalities for eradicating malignant tumors. RT is a good alternative to surgery for long-term control of many tumors of the head and neck, lung, cervix, bladder, prostate and skin, where it often achieves a reasonable probability of tumor control [1]. Standard conventional RT for tumor treatment consists of daily exposures to a fractionated dose of around 2 Gy for 5 - 7 weeks. Although tumors receive a large total dose through multiple fractionated radiation exposures (FR), they sometimes recur with radioresistance [2]. The existence of radioresistant cells remains one of the most critical obstacles for RT. Therefore, we have defined “clinically relevant radioresistant (CRR) cells" as cells which continue to grow, even after exposure to 2 Gy/day of X-rays for more than 30 days in vitro [3]. In order to understand the mechanisms involved in cellular radioresistance and to develop more effective radiotherapy, we have established CRR cell lines [3]-[9]. It was shown that the CRR cells acquired radioresistance through the activation of the serine/ threonine protein kinase B (PKB, also known as AKT) survival signaling pathway [5] [7] [8]. This pathway controls cellular "on-off switches" related to apoptosis and autophagy which are induced by radiation [10]. Autophagy is a programmed cell death mode like apoptosis, but is different from other cell death modes because of the presence of autophagosomes, autolysosomes and an intact nucleus in the cell [11]. In addition, the activation of AKT-related signaling was reported to enhance cancer stem cell (CSC) phenotypes [7] [12]. The CSC theory hypothesizes that tumors contain heterogeneous cell populations and that tumor growth is driven by a discrete subpopulation of CSCs which are defined by their capacity for self-renewal and by their ability to generate heterogeneous lineages of cancer cells [13]. These CSCs can provide a reservoir of cells which can lead to tumor recurrence, even after RT, through the presence of efficient DNA repair machinery and a resistance to apoptosis [14]-[16]. Thus, a cell's fate might be determined by a balance between cell survival and death after irradiation through AKT survival signaling.

Heavy charged particle RT using carbon ions (C-ions) is a newly emerging and promising therapy which can offer several advantages over conventional RT. C-ion beams have an excellent dose distribution for treating malignant tumors [17]. Clinical studies performed on various cancers have provided evidence that local control and survival rates for C-ion RT are higher than that for conventional RT [18]-[20]. Recently, we demonstrated that charged particle radiation depresses AKT-related survival signaling [21]. Therefore, we speculated that C-ion beams may enhance apoptosis and/or autophagy, and may target CSCs via the depression of AKT survival signaling in X-ray resistant cancer cells.

In this paper, to more clearly define the effect of C-ion beams on radiosensitivity, mode of cell death, cell signaling and the population of CSCs, X-ray resistant tumor cells were used which were capable of proliferation when subjected to daily X-ray exposures.

\section{Materials and Methods}

\subsection{Cell Lines}

The cell lines used in these studies were human SAS head and neck squamous carcinoma cells (HNSCC) obtained from the Cell Resource Center for Biomedical Research, Institute of Development, Aging and Cancer, Tohoku University. SAS-R cells were derived from SAS cells grown under daily exposures to 2 Gy of X-rays [4] (total irradiation dose: 2278 Gy). Cryo-preserved cells were used after 1 week of growth in culture without irradiation. Cells were cultured in DMEM-10 (Dulbecco’s modified Eagle’s medium) containing 10\% (v/v) fetal bovine serum, $20 \mathrm{mM}$ 2-[4-(2-hydroxyethyl)-1-piperazinyl] ethanesulfonic acid, penicillin (50 units/ml) and streptomycin $(50 \mu \mathrm{g} / \mathrm{ml})$. Cells were cultured at $37^{\circ} \mathrm{C}$ in a conventional humidified $\mathrm{CO}_{2}$ incubator.

\subsection{Irradiation}

Exponentially growing cells were irradiated at room temperature with X-rays and C-ion beams. X-irradiation was delivered by a 200-kVp X-ray generator (TITAN-225S, Shimadzu, Kyoto, Japan) with a total filtration of $0.5 \mathrm{~mm}$ aluminum plus 0.5 -mm copper. The X-ray dose rate was about $1.3 \mathrm{~Gy} / \mathrm{min}$ which was measured using a thimble ionization chamber (PTW FREIBURG, Freiburg, Germany) at the sample position. C-ion beam irradiation (290 MeV/nucleon, 6-cm spread-out Bragg peak (SOBP): $50 \mathrm{keV} / \mu \mathrm{m}$ ) [17] was performed in the Gunma University Heavy Ion Medical Center (GHMC, Gunma, Japan) [22]. Each irradiation was performed through a $3.5 \mathrm{~mm}$ layer of culture medium and a $1 \mathrm{~mm}$ plastic cover in a Nunc ${ }^{\mathrm{TM}}$ flask or multidish (Thermo Fisher Scien- 
tific, Waltham, MA).

\subsection{Modified High-Density Survival Assay}

Cell survival was determined with the modified high-density survival (HDS) assay [4] [23]. Briefly, $4 \times 10^{4}$ exponentially growing cells were seeded into a $\varphi 15 \mathrm{~mm}$ Nunc ${ }^{\mathrm{TM}}$ multidish (Thermo Fisher Scientific). After a $24 \mathrm{~h}$ incubation, cells were exposed to various doses of X-rays or C-ion beams and incubated for another $72 \mathrm{~h}$. Subsequently, cells from each flask were seeded into another $25 \mathrm{~cm}^{2}$ flask and incubated for further $72 \mathrm{~h}$. The total number of cells in each flask was then counted using the trypan blue dye exclusion test using a TC10 ${ }^{\mathrm{TM}}$ automated cell counter (BIO-RAD, Hercules, CA). Cell survival was plotted and the relative biological effectiveness (RBE) value of C-ion beams was compared to X-rays at a $20 \%$ survival dose $\left(D_{20}\right)$.

\subsection{Analysis of Nuclear Size}

Attached and floating cells were collected using trypsin at $72 \mathrm{~h}$ after irradiation. The cells were fixed with $1 \%$ glutaraldehyde in PBS at $4^{\circ} \mathrm{C}$, washed with PBS, stained with $0.2 \mathrm{mM}$ Hoechst 33342 (Nacalai Tesque, Kyoto, Japan), and then observed under a BZ-9000 fluorescent microscope (Keyence, Tokyo, Japan). The nucleus size in the cells was analyzed using the Duolink ${ }^{\circledR}$ ImageTool (Olink Bioscience, Uppsala, Sweden). Cells with a nucleus with an area of less than $10 \mu \mathrm{m}^{2}$ were considered pyknotic. Cells with a nucleus with an area of over 50 $\mu \mathrm{m}^{2}$ were considered as polyploid. A minimum of 500 cells was counted in every sample, and the percentage of pyknotic and polyploid cells was recorded.

\subsection{Analysis of Autophagy}

At $72 \mathrm{~h}$ after irradiation, the cells were stained with a Cyto-ID ${ }^{\circledR}$ Autophagy Detection kit (Enzo Life Sciences, Farmingdale, NY). The frequency of Cyto-ID ${ }^{\circledR}$ green stained autophagic vacuoles was measured using a flow cytometer (FACSCalibur $^{\mathrm{TM}}$, Becton Dickinson, San Jose, CA).

\subsection{Cell Survival Signaling Assay}

At $3 \mathrm{~h}$ after irradiation, cells were stained with a FlowCellect ${ }^{\mathrm{TM}}$ PI3K-mTOR Signaling Cascade Mapping Kit (Merck Millipore, Darmstadt, Germany). The phosphorylation of AKT (Ser473) and ribosomal protein S6 (rps6) (Ser235) proteins was measured using a flow cytometer.

\subsection{Cell Death Signaling Assay}

At $72 \mathrm{~h}$ after irradiation, cells were stained with a Vybrant ${ }^{\circledR} \mathrm{FAM}^{\mathrm{TM}}$ Poly Caspase Assay Kit (Invitrogen ${ }^{\mathrm{TM}}$, Thermo Fisher Scientific). The activation of pan-caspase was measured using a flow cytometer.

\subsection{Analysis of Cancer Stem-Like Cells}

CSCs are typically recognized by virtue of their expression of cell surface markers such as CD44 and CD326 (EpCAM) in HNSCC [24] [25]. At $72 \mathrm{~h}$ after irradiation, the cells were labeled with putative CSC markers, human monoclonal CD44 antibodies conjugated to fluorescein isothiocyanate (FITC) (Miltenyi Biotec K. K., Bergisch Gladbach, Germany) and human monoclonal CD326 antibodies conjugated to phycoerythrin (PE) (Miltenyi Biotec). The frequency of CD44 and CD326 positive cells was measured using a flow cytometer.

\subsection{Statistics}

The data from three independent experiments were expressed as mean values with standard deviations. The statistical significance was tested with the Student's $t$-test. A $p$ value of $<0.05$ was considered to be statistically significant.

\section{Results}

\subsection{C-Ion Beams Efficiently Induced Cell Killing in X-Ray-Resistant Cells}

The $D_{20}$ dose of X-rays was 7.5 Gy and 12.0 Gy in SAS cells and SAS-R cells, respectively. The $D_{20}$ dose of 
C-ion beams was 3.0 Gy and 3.2 Gy in SAS cells and SAS-R cells, respectively. After exposure to X-rays, SAS-R cells were found to be 1.6 times more radioresistant than SAS cells, although the cell survival rate was similar in each cell line after exposure to C-ion beams (Figure 1). The RBE at a $D_{20}$ dose in SAS cells and SAS-R cells was 3.8 and 2.5 , respectively.

Changes in nuclear size were analyzed using Hoechst 33342 staining at $72 \mathrm{~h}$ after irradiation (Figure 2). Figure 2(c) and Figure 2(d) show X-ray and C-ion beam induced pyknotic and polyploid cells appearing in a

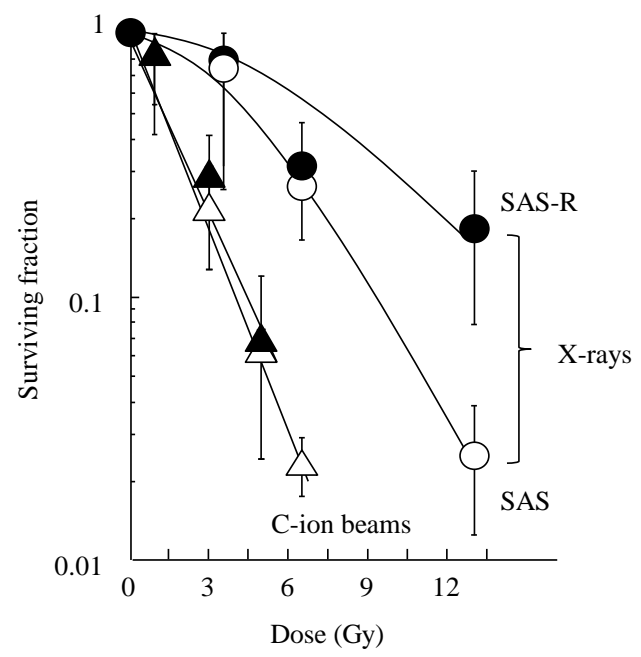

Figure 1. Cell survival measured with the modified high-density survival assay. Open symbols, SAS cells; closed symbols, SAS-R cells. Circles, X-rays; triangles, C-ion beams.

(a)

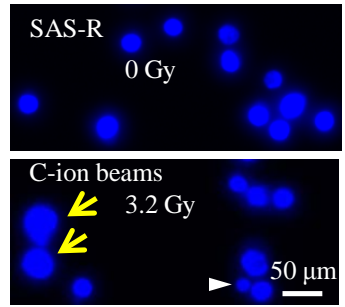

(c)

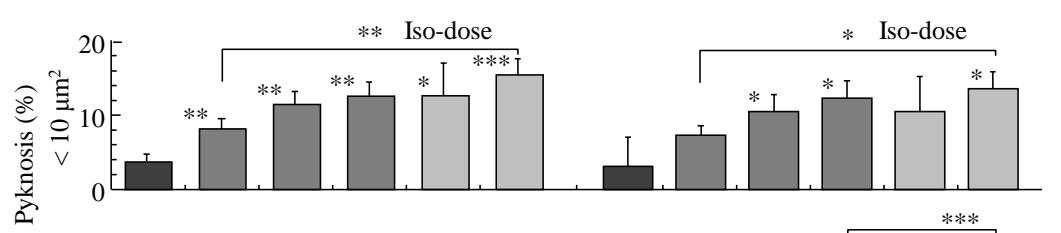

(d)

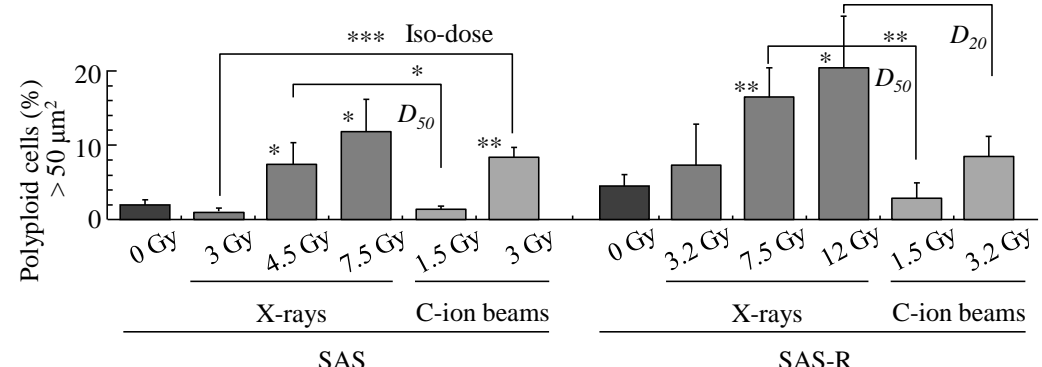

Figure 2. Changes in nuclear size at $72 \mathrm{~h}$ after irradiation in SAS and SAS-R cells. Note that the labels on the bottom of the figure below panel (d) apply to all of the panels (b), (c), and (d). (a) Photograph (400×) using Hoechst 33342 staining in unirradiated and irradiated SAS-R cells; (b) Chart showing nuclear sizes in SAS-R cells; (c) The frequency of pyknosis; (d) The frequency of polyploid cells. Error bars indicate standard deviations. Data were statistically evaluated with the Student's $t$-test between unirradiated cells and irradiated cells, and between the samples connected with a fine line $\left({ }^{*} p<0.05,{ }^{* *} p<0.01\right.$, and $\left.{ }^{* * * *} p<0.001\right)$. 
dose-dependent manner in SAS cells and SAS-R cells. At the iso-doses, the frequency of hyperinduced pyknosis was greater in C-ion irradiated cells than in X-irradiated cells. At the iso-survival doses obtained from the HDS assay, although no significant differences in the induction of pyknosis were observed in either cell line (Figure 2(c)), C-ion beams suppressed the appearance of polyploid cells (Figure 2(d)).

The basal level of Cyto-ID ${ }^{\circledR}$ green positive-stained autophagic vacuoles was detected at high levels in SASR cells when compared to SAS cells (Figure 3(c)). At iso-doses, C-ion beams induced autophagy when compared to X-rays in both cell lines. Even at iso-survival doses, the C-ion beams induced notably higher levels of autophagy when compared to X-rays in SAS-R cells.

\subsection{C-Ion Beams Suppressed Cell Survival Signaling and Induced Cell Death Signaling in X-Ray Resistant Cells}

The activation of poly-caspase leading to cell death signaling was analyzed at $72 \mathrm{~h}$ after irradiation (Figure 4(a)). X-rays and C-ion beams induced the activation of poly-caspase in a dose-dependent manner in SAS-R cells. At iso-survival doses, activation was greater in C-ion irradiated cells than in X-irradiated cells.

The expression of phospho-AKT (p-AKT) and phospho-rpS6 (p-rpS6) cell survival signals was analyzed at 3 $\mathrm{h}$ after irradiation (Figure 4(b) and Figure 4(c)). The expression of both p-AKT and p-rpS6 was highly activated in SAS-R cells when compared to SAS cells in non-irradiated cells. X-rays and C-ion beams suppressed the expression in a dose-dependent manner in SAS-R cells. Not only at the iso-doses but also at $D_{50}$ and $D_{20}$ iso-survival doses, their expression was suppressed more efficiently in C-ion irradiated cells than in X-irradiated cells.

\subsection{Cancer Stem-Like Cell Numbers Decreased Significantly after Exposure to C-Ion Beams}

Cells were labeled with the putative CSC markers CD44 and CD326. Basal levels of double labeled positive

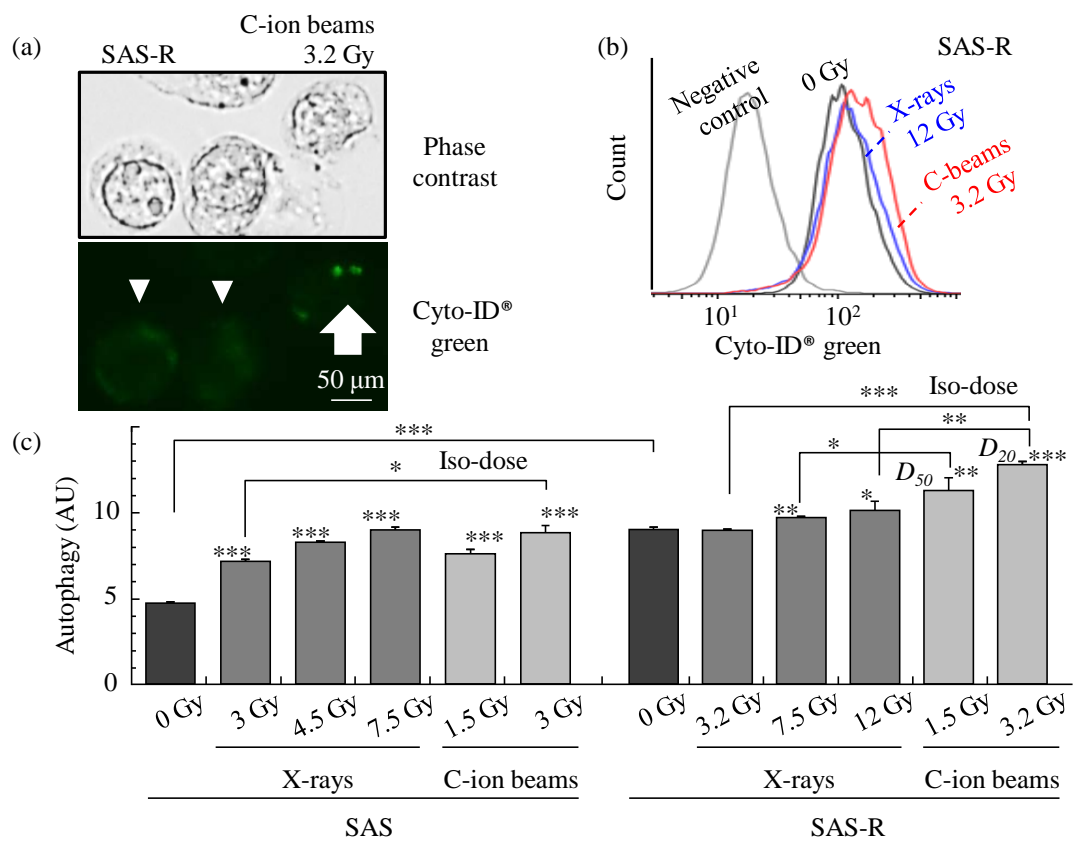

Figure 3. Stained autophagic vacuoles at $72 \mathrm{~h}$ after irradiation in SAS and SAS-R cells. (a) Photograph $(400 \times)$ using phase contrast and fluorescent microscopy in 3.2 Gy C-ion irradiated SAS-R cells. Autophagy is indicated by the heavily stained autophagic vacuoles (arrow) and in normal cells (arrow heads); (b) Graph showing numbers of Cyto-ID ${ }^{\circledR}$ green stained cells; (c) The frequency of autophagy. AU, arbitrary unit. Error bars indicate standard deviations. Data were statistically evaluated with the Student's $t$-test between unirradiated cells and irradiated cells, and between the samples connected with the lines $\left({ }^{*} p<0.05,{ }^{* *} p<0.01\right.$, and $\left.{ }^{* * *} p<0.001\right)$. 
(a)

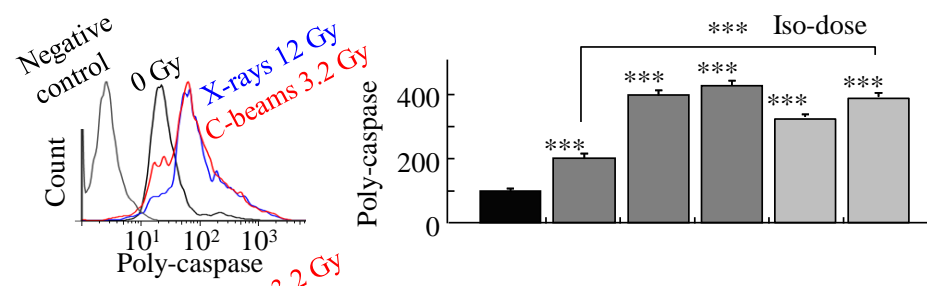

(b)
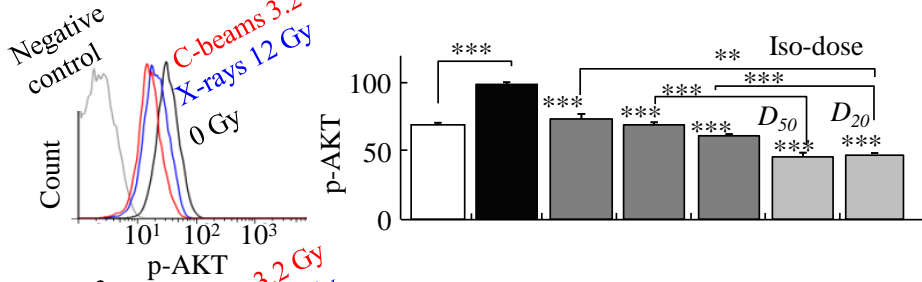

(c)
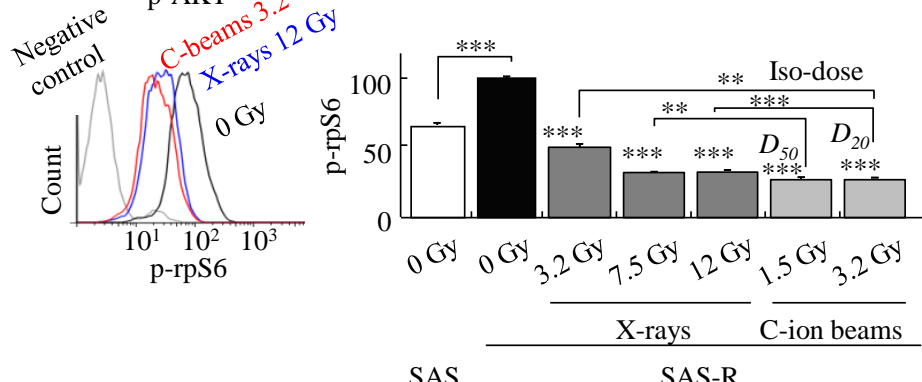

\begin{abstract}
Figure 4. Cell death signaling and cell survival signaling at $72 \mathrm{~h}$ (a) and $3 \mathrm{~h}$ (b) and (c) after irradiation of SAS-R cells. The right panels show the relative values of poly-caspase activation (a), p-AKT expression (b) and p-rps6 expression (c) using the value in untreated SAS-R cells as a standard value of 100. The left panels show typical graphs illustrating the number of stained cells in each group. Note that the labels below panel (c) apply to all of the panels, (a), (b), and (c). The error bars indicate standard deviations. Data were statistically evaluated with the Student's $t$-test between unirradiated cells and irradiated cells, and between the samples connected with the lines $\left(^{*} p<0.05\right.$, ${ }^{* *} p<0.01$, and $\left.{ }^{* * * *} p<0.001\right)$.
\end{abstract}

cells were higher in non-irradiated SAS-R cells compared to SAS cells (Figure 5). The number of double positive cells increased in a dose-dependent manner after exposure to X-rays and C-ion beams. At the $D_{50}$ and $D_{20}$ iso-survival doses, the number of double positive cells showed a significantly larger decrease after exposure to C-ion beams than to X-rays.

\title{
4. Discussions
}

The biological advantages of using C-ion beams were a higher RBE [26] [27], a decreased oxygen enhancement ratio [28], a diminished capacity for DNA repair of cellular radiation injuries [29], and the potential suppression of metastases [30].

This study clearly demonstrated that C-ion beams efficiently induced cell killing in X-ray-resistant cells (Figure 1). These findings agree with previous results published by our group [31]-[33] which demonstrated that the RBE of heavy-ion beams in X-ray resistant $p 53$-dysfunctional cells was higher than in X-ray sensitive wild-type $p 53$ cells. Apoptosis was induced more efficiently when cells were exposed to heavy-ion beams than to X-rays, regardless of $p 53$ gene status [31]-[33]. In SAS and SAS-R cells, although the contribution of apoptosis to cellular radiosensitivity is lower than previously thought [6], hyperinduced pyknosis was detected and was greater in C-ion irradiated cells than in X-irradiated cells at iso-doses (Figure 2(c)). Pyknosis is the irreversible condensation of chromatin in the nucleus of a cell undergoing apoptosis [11]. On the other hand, polyploid cells were present at lower levels in C-ion irradiated cells than in X-ray irradiated cells at iso-survival doses (Figure 2(d)). Radiation-induced polyploid cells usually suffer cell death from mitotic catastrophe [34]. Mitotic catastrophe has been described in which mitotic failure is sensed and the cell responds by following a pathway to cell 


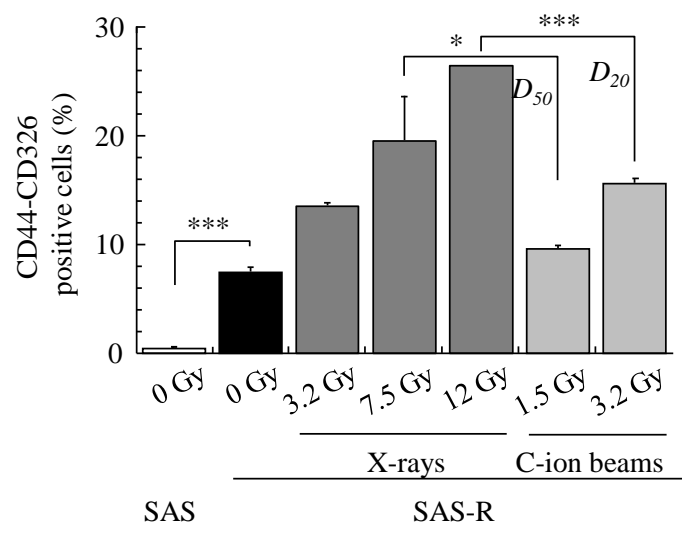

Figure 5. The frequency of CD44 and CD326 positive non-irradiated cells and in irradiated cells at 72 $\mathrm{h}$ after irradiation in SAS-R cells. Error bars indicate standard deviations. Data were statistically evaluated with the Student's $t$-test between unirradiated cells and irradiated cells, and between the samples connected with the lines $\left({ }^{*} p<0.05,{ }^{* * *} p<0.01\right.$, and $\left.{ }^{* * *} p<0.001\right)$.

death through apoptosis, necrosis, or senescence [35]. Autophagy has a bi-directional effect comparable to the two edges of a sword and the results can be cell death or cell survival [36]. Consistent with this concept, High basal levels of autophagy were detected in X-ray resistant SAS-R cells when compared to SAS cells here (Figure 3(c)) as well as in a previous report [6]. This basal level of autophagy may contribute to cell protection. On the other hand, autophagy was induced efficiently in each cell line after exposure to C-ion beams (Figure 3(c)). This result was supported by recent findings that C-ion beams can induce autophagy in various tumor cells effectively, and that the autophagy level in irradiated cells increased in a dose- and LET-dependent manner [37]. These results suggest that hyperinduced apoptosis and autophagy are associated with C-ion beam-induced cell death in SAS-R cells.

These results indicate that C-ion beams induce poly-caspase activity (Figure 4(a)) and suppress AKT signaling (Figure 4(b) and Figure 4(c)) and, and this concurs well with previous findings [21]. Recently, it was also reported that the ability of C-ion beams to inhibit the activation of the AKT pathway increased with increasing LET values [37]. AKT signaling can also block cell death signaling pathways by regulating various target molecules such as apoptosis related proteins [38] [39].

C-ion beams may simultaneously kill both non-CSCs and CSCs; consequently, the cell population of CSCs was only slightly increased or unchanged (Figure 5). If CSCs were eliminated, a cancer would be unable to grow and unable to spread to other locations in the body. Recently, it was reported that C-ion beams targeted cancer stem-like cells in the colon and pancreas [40] [41].

\section{Conclusion}

These results suggest that C-ion beams may enhance apoptosis and autophagy through the activation of death signaling, and may target CSCs via the depression of AKT survival signaling in X-ray resistant cancer cells. Therefore, the concept of a C-ion augmentation therapy delivered to recurrent patients with clinically radio-resistant cells after conventional RT might offer a promising treatment alternative or supplement. More detailed studies are necessary to define the initial events which occur during the depression of AKT survival signaling after exposure to C-ion beams.

\section{Acknowledgements}

This work was supported in part by grants from the Ministry of Education, Culture, Sports, Science and Technology of Japan (MEXT) and the Program to Disseminate the Tenure Tracking System of MEXT granted to Gunma University. The study was performed as part of the Research Project with heavy ions at the Gunma 
University Heavy Ion Medical Center (GHMC, Gunma University).

\section{References}

[1] Joiner, M.C., van der Kogel, A.J. and Steel, G.G. (2009) Introduction: The Significance of Radiobiology and Radiotherapy for Cancer Treatment. In: Joiner, M. and van der Kogel, A., Eds., Basic Clinical Radiobiology Fourth Edition, Hodder Arnold Publication, London, 1-10. http://dx.doi.org/10.1201/b13224-2

[2] Kim, J.J. and Tannock, I.F. (2005) Repopulation of Cancer Cells during Therapy: An Important Cause of Treatment Failure. Nature Reviews Cancer, 5, 516-525.

[3] Kuwahara, Y., Li, L., Baba, T., Nakagawa, H., Shimura, T., Yamamoto, Y., Ohkubo, Y. and Fukumoto, M. (2009) Clinically Relevant Radioresistant Cells Efficiently Repair DNA Double-Strand Breaks Induced by X-Rays. Cancer Science, 100, 747-752.

[4] Kuwahara, Y., Mori, M., Oikawa, T., Shimura, T., Ohtake, Y., Mori, S., Ohkubo, Y. and Fukumoto, M. (2010) The Modified High-Density Survival Assay Is the Useful Tool to Predict the Effectiveness of Fractionated Radiation Exposure. Journal of Radiation Research, 51, 297-302. http://dx.doi.org/10.1269/jrr.09094

[5] Shimura, T., Kakuda, S., Ochiai, Y., Nakagawa, H., Kuwahara, Y., Takai, Y., Kobayashi, J., Komatsu, K. and Fukumoto, M. (2010) Acquired Radioresistance of Human Tumor Cells by DNA-PK/AKT/GSK3 Beta-Mediated Cyclin D1 Overexpression. Oncogene, 29, 4826-4837.

[6] Kuwahara, Y., Oikawa, T., Ochiai, Y., Roudkenar, M.H., Fukumoto, M., Shimura, T., Ohtake, Y., Ohkubo, Y., Mori, S., Uchiyama, Y. and Fukumoto, M. (2011) Enhancement of Autophagy Is a Potential Modality for Tumors Refractory to Radiotherapy. Cell Death and Disease, 30, e177.

[7] Shimura, T., Noma, N., Oikawa, T., Ochiai, Y., Kakuda, S., Kuwahara, Y., Takai, Y., Takahashi, A. and Fukumoto, M. (2012) Activation of the AKT/Cyclin D1/Cdk4 Survival Signaling Pathway in Radioresistant Cancer Stem Cells. Oncogenesis, 1, e12.

[8] Shimura, T., Ochiai, Y., Noma, N., Oikawa, T., Sano, Y. and Fukumoto, M. (2013) Cyclin D1 Overexpression Perturbs DNA Replication and Induces Replication-Associated DNA Double-Strand Breaks in Acquired Radioresistant Cells. Cell Cycle, 12, 773-782.

[9] Kuwahara, Y., Mori, M., Kitahara, S., Fukumoto, M., Ezaki, T., Mori, S., Echigo, S., Ohkubo, Y. and Fukumoto, M. (2014) Targeting of Tumor Endothelial Cells Combining 2 Gy/Day of X-Ray with Everolimus Is the Effective Modality for Overcoming Clinically Relevant Radioresistant Tumors. Cancer Medicine, 3, 310-321.

[10] Moretti, L., Cha, Y.I., Niermann, K.J. and Lu, B. (2007) Switch between Apoptosis and Autophagy: Radiation-Induced Endoplasmic Reticulum Stress? Cell Cycle, 6, 793-798. http://dx.doi.org/10.4161/cc.6.7.4036

[11] Kroemer, G., Galluzzi, L., Vandenabeele, P., Abrams, J., Alnemri, E.S., Baehrecke, E.H., Blagosklonny, M.V., ElDeiry, W.S., Golstein, P., Green, D.R., Hengartner, M., Knight, R.A., Kumar, S., Lipton, S.A., Malorni, W., Nuñez, G., Peter, M.E., Tschopp, J., Yuan, J., Piacentini, M., Zhivotovsky, B. and Melino, G. (2009) Classification of Cell Death: Recommendations of the Nomenclature Committee on Cell Death 2009. Cell Death and Differentiation, 16, 3-11.

[12] Chang, L., Graham, P.H., Hao, J., Ni, J., Bucci, J., Cozzi, P.J., Kearsley, J.H. and Li, Y. (2013) Acquisition of Epithelial-Mesenchymal Transition and Cancer Stem Cell Phenotypes Is Associated with Activation of the PI3K/ Akt/mTOR Pathway in Prostate Cancer Radioresistance. Cell Death and Disease, 4, e875.

[13] Pardal, R., Clarke, M.F. and Morrison, S.J. (2003) Applying the Principles of Stem-Cell Biology to Cancer. Nature Reviews Cancer, 3, 895-902.

[14] Bao, S., Wu, Q., McLendon, R.E., Hao, Y., Shi, Q., Hjelmeland, A.B., Dewhirst, M.W., Bigner, D.D. and Rich, J.N. (2006) Glioma Stem Cells Promote Radioresistance by Preferential Activation of the DNA Damage Response. Nature, 444, 756-760.

[15] Baumann, M., Krause, M. and Hill, R. (2008) Exploring the Role of Cancer Stem Cells in Radioresistance. Nature Reviews Cancer, 8, 545-554.

[16] Nguyen, G.H., Murph, M.M. and Chang, J.Y. (2011) Cancer Stem Cell Radioresistance and Enrichment: Where Frontline Radiation Therapy May Fail in Lung and Esophageal Cancers. Cancers, 3, 1232-1252. http://dx.doi.org/10.3390/cancers3011232

[17] Kanai, T., Furusawa, Y., Fukutsu, K., Itsukaichi, H., Eguchi-Kasai, K. and Ohara, H. (1997) Irradiation of Mixed Beam and Design of Spread-Out Bragg Peak for Heavy-Ion Radiotherapy. Radiation Research, 147, 78-85. http://dx.doi.org/10.2307/3579446

[18] Tsujii, H. and Kamada, T. (2007) A Review of Update Clinical Results of Carbon Ion Radiotherapy. Japanese Journal of Clinical Oncology, 42, 670-685. http://dx.doi.org/10.1093/jico/hys104

[19] Durante, M. and Loeffler, J.S. (2010) Charged Particles in Radiation Oncology. Nature Reviews Clinical Oncology, 7, 
37-43. http://dx.doi.10.1038/nrclinonc. 2009.183

[20] Ohno, T. (2013) Particle Radiotherapy with Carbon Ion Beams. The EPMA Journal, 4, 9. http://dx.doi.org/10.1186/1878-5085-4-9

[21] Nakagawa, Y., Takahashi, A., Kajihara, A., Yamakawa, N., Imai, Y., Ota, I., Okamoto, N., Mori, E., Noda, T., Furusawa, Y., Kirita, T. and Ohnishi, T. (2012) Depression of p53-Independent Akt Survival Signals in Human Oral Cancer Cells Bearing Mutated p53 Gene after Exposure to High-LET Radiation. Biochemical and Biophysical Research Communications, 423, 654-660. http://dx.doi.org/10.1016/j.bbrc.2012.06.004

[22] Ohno, T., Kanai, T., Yamada, S., Yusa, K., Tashiro, M., Shimada, H., Torikai, K., Yoshida, Y., Kitada, Y., Katoh, H., Ishii, T. and Nakano, T. (2011) Carbon Ion Radiotherapy at the Gunma University Heavy Ion Medical Center: New Facility Set-Up. Cancers, 3, 4046-4060. http://dx.doi.org/10.3390/cancers3044046

[23] Mirzayans, R., Andrais, B., Scott, A., Tessier, A. and Murray, D. (2007) A Sensitive Assay for the Evaluation of Cytotoxicity and Its Pharmacologic Modulation in Human Solid Tumor-Derived Cell Lines Exposed to Cancer-Therapeutic Agents. Journal of Pharmacy and Pharmaceutical Sciences, 10, 298s-311s.

[24] Han, J., Fujisawa, T., Husain, S.R. and Puri, R.K. (2014) Identification and Characterization of Cancer Stem Cells in Human Head and Neck Squamous Cell Carcinoma. BMC Cancer, 14, 173. http://dx.doi.org/10.1186/1471-2407-14-173

[25] Waldron, N.N., Barsky, S.H., Dougherty, P.R. and Vallera, D.A. (2014) A Bispecific EpCAM/CD133-Targeted Toxin Is Effective against Carcinoma. Targeted Oncology, in press.

[26] Ando, K. and Kase, Y. (2009) Biological Characteristics of Carbon-Ion Therapy. International Journal of Radiation Biology, 85, 715-728. http://dx.doi.org/10.1080/09553000903072470

[27] Suzuki, M., Kase, Y., Yamaguchi, H., Kanai, T. and Ando, K. (2000) Relative Biological Effectiveness for Cell-Killing Effect on Various Human Cell Lines Irradiated with Heavy-Ion Medical Accelerator in Chiba (HIMAC) Carbon-Ion Beams. International Journal of Radiation Oncology, Biology, Physics, 48, 241-250. http://dx.doi.org/10.1016/S0360-3016(00)00568-X

[28] Hirayama, R., Furusawa, Y., Fukawa, T. and Ando, K. (2005) Repair Kinetics of DNA-DSB Induced by X-Rays or Carbon Ions under Oxic and Hypoxic Conditions. Journal of Radiation Research, 46, 325-332. http://dx.doi.org/10.1269/jrr.46.325

[29] Takahashi, A., Yamakawa, N., Kirita, T., Omori, K., Ishioka, N., Furusawa, Y., Mori, E., Ohnishi, K. and Ohnishi, T. (2008) DNA Damage Recognition Proteins Localize along Heavy Ion Induced Tracks in the Cell Nucleus. Journal of Radiation Research, 49, 645-652. http://dx.doi.org/10.1269/jrr.08007

[30] Akino, Y., Teshima, T., Kihara, A., Kodera-Suzumoto, Y., Inaoka, M., Higashiyama, S., Furusawa, Y. and Matsuura, N. (2009) Carbon-Ion Beam Irradiation Effectively Suppresses Migration and Invasion of Human Non-Small-Cell Lung Cancer Cells. International Journal of Radiation Oncology, Biology, Physics, 75, 475-481. http://dx.doi.org/10.1016/j.ijrobp.2008.12.090

[31] Takahashi, A., Ohnishi, K., Ota, I., Asakawa, I., Tamamoto, T., Furusawa, Y., Matsumoto, H. and Ohnishi, T. (2001) p53-Dependent Thermal Enhancement of Cellular Sensitivity in Human Squamous Cell Carcinomas in Relation to LET. International Journal of Radiation Biology, 77, 1043-1051. http://dx.doi.org/10.1080/09553000110066095

[32] Takahashi, A., Matsumoto, H., Yuki, K., Yasumoto, J., Kajihara, A., Aoki, M., Furusawa, Y., Ohnishi, K. and Ohnishi, T. (2004) High-LET Radiation Enhanced Apoptosis But Not Necrosis Regardless of $p 53$ Status. International Journal of Radiation Oncology, Biology, Physics, 60, 591-597. http://dx.doi.org/10.1016/j.ijrobp.2004.05.062

[33] Takahashi, A., Matsumoto, H., Furusawa, Y., Ohnishi, K., Ishioka, N. and Ohnishi, T. (2005) Apoptosis Induced by High-LET Radiations Is Not Affected by Cellular p53 Gene Status. International Journal of Radiation Biology, 81, 581-586. http://dx.doi.org/10.1080/09553000500280484

[34] Vakifahmetoglu, H., Olsson, M. and Zhivotovsky, B. (2008) Death through a Tragedy: Mitotic Catastrophe. Cell Death and Differentiation, 15, 1153-1162. http://dx.doi.org/10.1038/cdd.2008.47

[35] Vitale, I., Galluzzi, L., Castedo, M. and Kroemer, G. (2011) Mitotic Catastrophe: A Mechanism for Avoiding Genomic Instability. Nature Reviews Molecular Cell Biology, 12, 385-392. http://dx.doi.org/10.1038/nrm3115

[36] Shintani, T. and Klionsky, D.J. (2004) Autophagy in Health and Disease: A Double-Edged Sword. Science, 306, 990-995. http://dx.doi.org/10.1126/science.1099993

[37] Jin, X., Liu, Y., Ye, F., Liu, X., Furusawa, Y., Wu, Q., Li, F., Zheng, X., Dai, Z. and Li, Q. (2014) Role of Autophagy in High Linear Energy Transfer Radiation-Induced Cytotoxicity to Tumor Cells. Cancer Science, 105, 770-778. http://dx.doi.org/10.1111/cas.12422

[38] Nicholson, K.M. and Anderson, N.G. (2002) The Protein Kinase B/Akt Signalling Pathway in Human Malignancy. Cell Signaling, 14, 381-395. http://dx.doi.org/10.1016/S0898-6568(01)00271-6

[39] Duronio, V. (2008) The Life of a Cell: Apoptosis Regulation by the PI3K/PKB Pathway. The Biochemical Journal, 
415, 333-344. http://dx.doi.org/10.1042/BJ20081056

[40] Cui, X., Oonishi, K., Tsujii, H., Yasuda, T., Matsumoto, Y., Furusawa, Y., Akashi, M., Kamada, T. and Okayasu, R. (2011) Effects of Carbon Ion Beam on Putative Colon Cancer Stem Cells and Its Comparison with X-Rays. Cancer Research, 71, 3676-3687. http://dx.doi.org/10.1158/0008-5472.CAN-10-2926

[41] Oonishi, K., Cui, X., Hirakawa, H., Fujimori, A., Kamijo, T., Yamada, S., Yokosuka, O. and Kamada, T. (2012) Different Effects of Carbon Ion Beams and X-Rays on Clonogenic Survival and DNA Repair in Human Pancreatic Cancer Stem-Like Cells. Radiotherapy and Oncology, 105, 258-265. http://dx.doi.org/10.1016/j.radonc.2012.08.009 
Scientific Research Publishing (SCIRP) is one of the largest Open Access journal publishers. It is currently publishing more than 200 open access, online, peer-reviewed journals covering a wide range of academic disciplines. SCIRP serves the worldwide academic communities and contributes to the progress and application of science with its publication.

Other selected journals from SCIRP are listed as below. Submit your manuscript to us via either submit@scirp.org or Online Submission Portal.
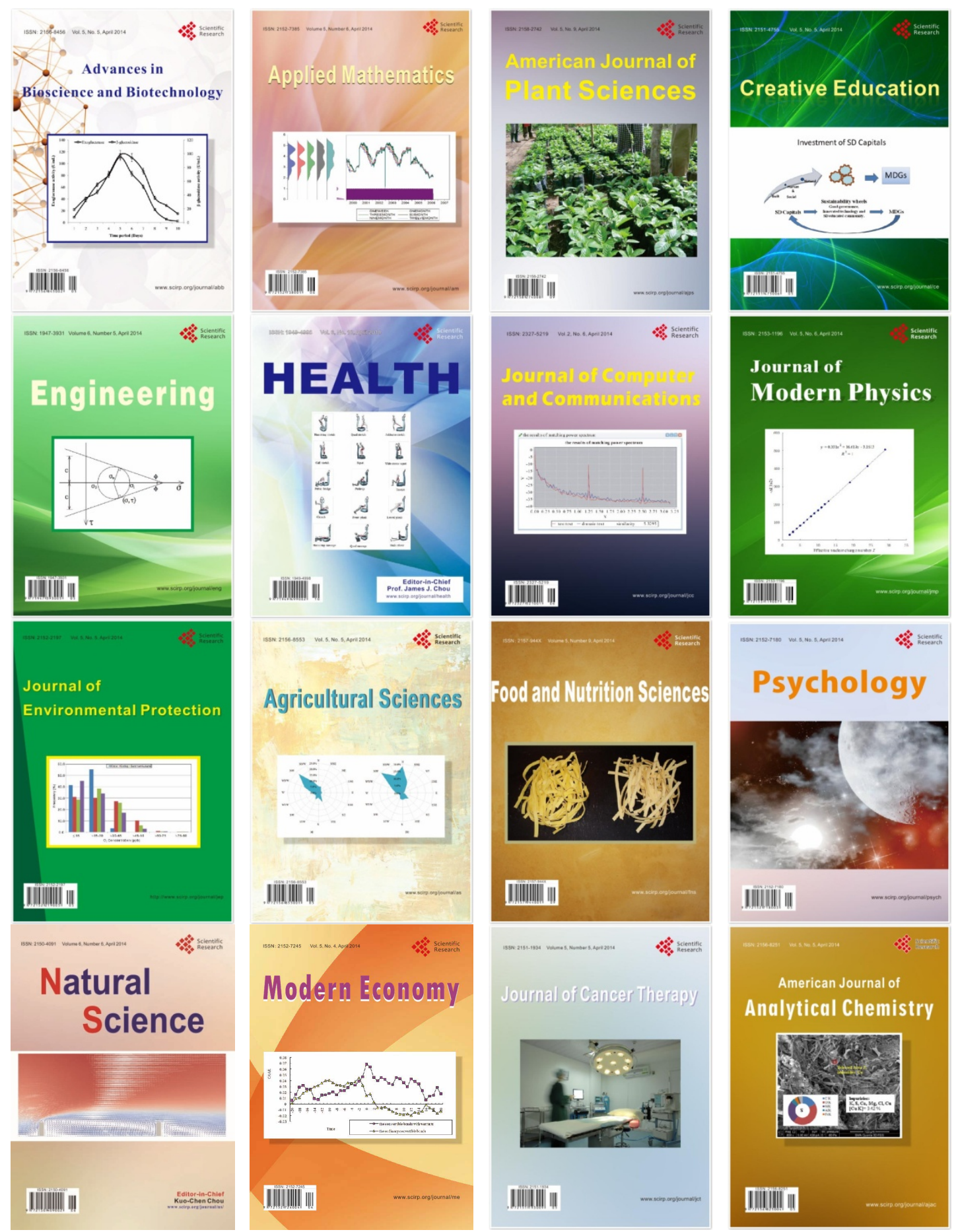